\title{
LANGUAGE OF SAPTARIYA THARU
}

\section{Mahesh Kumar Chaudhary}

Tribhuvan University

mauskchy@yahoo.com

\section{Abstract}

The purpose of this paper is to present a general overview of the Tharu language as it is spoken in Saptari District. Geographical distribution of Tharu, its genetic affiliation, linguistics characteristics; phonology, morphology and syntax are looked into brief. This paper is based mainly on primary sources alongwith secondary one.

Key Words: Tharu, Phonology, Morphology, Syntax

\section{Background}

The language, which is spoken by the Tharu people, is known by the name Tharu. It has some regional variations, and they are known by the regional names. They are: Morangia Tharu, Saptariya/ KochilaTharu, Mahotari Tharu, Chitwania Tharu, Danguara Tharu, Kathoriya Tharu and Rana tharu. The Tharu lives along the terai belt and inner-terai of Nepal from its east border to the west border, starting from Jhapa district to Kanchanpur district. According to censing 2011 report, the total number of Tharu people is $17,37,740$ and the tharu speakers is 13,31,546. According to this report, Jhapa, Sunsari, Udayapur, Saptari, Siraha, Sarlahi, Rautahat, Bara, Chitwan, Nawalparasi, Rupandehi, Kapilvastu, Dang, Banke, Surkhet, Kailali and kanchanpur are the main districts where Tharu language is spoken. Among these districts, Kailali, Dang and Sunsari are the first, second and third districts in term of number of speakers having 249552, 138988 and 977630 mother tongue speakers, respectively. Tharu is an Indo-Aryan language of Indo-European family, as it resembles 
all the characteristics of Indo-Aryan branch. It is difficult to trace it exact development, and, hence, its affiliation. According to pokahrel (2050: 5) this language falls under the ardhamagadhi branch of indo- Aryan language family. Whereas Bandhu (2052: 12) has asserted that, this language has derived from Magadhi Prakrit under prachya Sanskrit of Indo-European language. In addition, according to Yadava, (2003: 8) the Tharu language falls under the Eastern and central group of Indo- Aryan branch of language family.

\section{Linguistic Characteristics}

The Tharu language shares various linguistic features of this region. It is postpositional and left-branching language. Like many other Indo-Aryan languages, it is verb final language. The basic word order in this language is SOV.

\section{Phonology}

As already stated this language is spoken from east through west of Nepal. There are found variations in the Tharu language spoken at different places. These different varieties represent the linguistic continuum of the Tharu. These varieties are: Eastern Tharu, Central Tharu, Mid-central Tharu and western Tharu. The phonology of each of the varieties is slightly different. Altogether there are thirty five phonemes, twenty nine consonants and six vowels.

\section{Consonants}

Table 1: Consonants phonemes in Tharu

\begin{tabular}{|c|c|c|c|c|c|c|}
\hline & Bilabial & Dental & Alveolar & Palatal & Velar & Glottal \\
\hline Stop & $\begin{array}{l}\mathrm{p} \\
\mathrm{b} \\
\mathrm{ph} \\
\mathrm{ph}\end{array}$ & $\begin{array}{l}\text { T } \\
d \\
\text { th } \\
\text { th }\end{array}$ & $\begin{array}{ll}\text { T } & \text { D } \\
\text { Th } & \\
\text { Dh } & \end{array}$ & & $\begin{array}{l}\mathrm{K} \\
\mathrm{g} \\
\mathrm{Kh} \\
\mathrm{gh}\end{array}$ & \\
\hline
\end{tabular}




\begin{tabular}{|l|r|r|rr|l|l|l|}
\hline Nasal & $\mathrm{m}$ & & $\mathrm{n}$ & & & \\
\hline Affricative & & & $\mathrm{c}$ & $\mathrm{j}$ & & & \\
& & & $\mathrm{ch}$ & $\mathrm{jh}$ & & & \\
\hline Fricative & & & $\mathrm{S}$ & & & $\mathrm{h}$ \\
\hline Trill & & & & $\mathrm{r}$ & & & \\
\hline Lateral & & & & $\mathrm{l}$ & & & \\
\hline Glide & w & & & & y & & \\
\hline
\end{tabular}

As it represented in the table, aspiration is contrastive in all the stops and affricates, e.g.,

peT 'stomach' pheT 'to mix', bul 'walk' bhul 'to forget' dur 'far' dhur 'ridge of terrace', gaam 'village' ghaam 'sweat', jar 'fever' jhar 'unnecessary thing'

\section{Vowels}

The following table shows the vowel phonemes.

Table 2: Vowel phonemes in Tharu

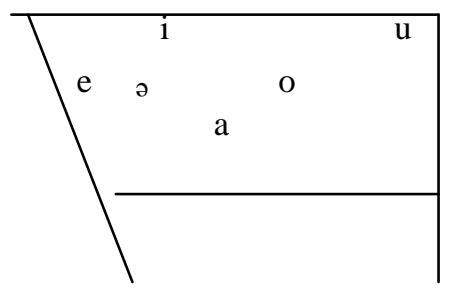

Six vowel phonemes; two fonts, two central and two back are found. Nasalization is contrastive and phonemic, e. $g$,

$$
\text { Mous 'mother's sister' mou } \sim \text { 'meat' }
$$

\section{Syllable}


In Tharu language, seven types of syllable patterns are found. $\mathrm{CV}$ is the most common pattern of syllable. The different syllable patterns are as follow:

i. V: $u$ 'he/'she', ii. CV : tu you' iii. CVC : kaam 'work', iv. CCV: syaaes' v. CCVC: byaah'marriage' vii. CCVC: blyaah 'difficult to hold' viii. VC : aam 'mango'

\section{Morphology}

Noun: Tharu nouns are distinguished for number, case and gender. - sab/sun is suffixed to the singular noun to mark plural number, e. g, Chouraa 'boy' chouraasab/sun 'boys', Cirai 'bird' ciraisab/ sun 'birds', Gaach 'tree' gaachsab /sun 'trees'. Sometimes, masculine and feminine nouns are distinguished by the inflection, e.g., Chauraa 'boy' chouri 'girl', Bhaginaa 'nephew' bhagini 'niece.'

\section{Pronoun}

Table 3: Tharu personal pronouns

\begin{tabular}{|l|l|l|}
\hline Person & Pronoun & Pronoun \\
\hline & Singular & Plural \\
\hline 1 & Ham & hamsab \\
\hline 2 & Tu/to/tuhe & tusab/tosab/tuhesab \\
\hline $2 \mathrm{H}$ & Apane & apanesab \\
\hline 3 & U & $\begin{array}{l}\text { ussun } \\
\text { Issun }\end{array}$ \\
\hline
\end{tabular}

Table 4: Tharu possessive pronouns

\begin{tabular}{|l|l|l|}
\hline Person & \multicolumn{1}{|c|}{7.} & \multicolumn{1}{|c|}{8.} \\
\hline & Singular & Plural \\
\hline
\end{tabular}




\begin{tabular}{|l|l|l|}
\hline 1 & Hamar & Hamarsun/ hamarke / hamrorke \\
\hline 2 & Tohar & toroeke / tuhesun \\
\hline $2 \mathrm{H}$ & Apane & Apansun \\
\hline 3 & Okar & Okrasab / okrarke \\
\hline
\end{tabular}

Two types of demonstrative pronouns are found, proximate and remote.

Proximate: i 'this' isab/isun 'these'

Remote: $u$ 'that' usab/isun 'those'

Ke 'who', koan 'which', katahek 'how much' kaihiyaa

'when', kakar 'whom' are interrogative pronouns

\section{Verb}

The verbs in this language can be classified into two classes: Simple verbs and derived verbs. Likh 'write' and baiTh 'sit' are the examples of simple verbs, whereas jaaile ' to go' are the examples of derived verbs as the latter are formed by adding - ile to the root.

The different verbal affixes used to form the second class of verbs in Tharu language are as follows:

- Ile is infinite marker, e.g., khaaile 'to eat', baiTheile 'to sit'.

- ite is progressive marker, e.g., khaaite 'eating'

- ne is perfective marker, e.g., khene [khaa + ne] 'had eaten'

- ake is absolutive marker, e.g., kairake 'after doing'

- $i$ marks imperfect aspect, e.g.,

(1) ham bhaat kha-I ci-e, I rice eat- IMPERF be- NPT 1

'I eat rice.'

$n_{\partial} i$ - is negative marker and always prefixed to the verb stem, e.g., (2) $u$ bhaat nai-khaa-I ch-ai, he/she rice NEGeat-IMPERF be- MPT 3, He/she does not eat rice.' 
Tense: Past, present and future are the three tenses founded in Tharu language.

Past tense: Regarding the past marker- lie is used for first person and- lihi is used for $2^{\text {nd }}$ person. Besides this, the suffix $-k a i$ is used for third person singular and plural both.

The verb kha - 'eat' is conjugated as follow:

$$
\begin{array}{ll}
\text { First person: } & \text { khe-lie } \\
\text { Second person: } & \text { khe-lihi } \\
\text { Third person: } & \text { khe-lkai }
\end{array}
$$

The verbs are inflected only for person, and not for number, gender or honoroficity of the subject.

Present tense: Suffix $-e$ is used for first person and $-h i$ is used for second person. Besides these, the suffix- $a i$ is for third person singular and plural both. Present tense forms of the verb khaa- 'eat' are as follow:

First person: khaa-i ci-e, Second person: khaa-i ci-hi, Third person: $\quad k h a a-i c h-a i$. In these examples, $-i$ attached to khaa- is imperfective marker.

Future tense: -bai, -bihi and -tai mark future tense in first, second and third persons, respectively. These suffixes also mark the meaning of probability, e.g., ham jebai 'I will go.'/'I may go.' tusab jebihi 'You(PL) will go.'/'You may go.' $u$ jetai 'She/He will go'. /'she/he may go.'

\section{Word Formation}

Following types of word formation are found in Thar $5 \mathrm{u}$ language.

Borrowing: Most of the words in this language are similar to the neighboring languages like Nepali, Hindi, Maithili, etc. The native Tharu speakers are borrowing many words from other languages. The borrowed words are easily uttered with 
their own pronunciation. For example- Likh -(Tharu), lekh(Nepali)'write. Suruj-(Tharu) suraj (Hindi) 'sun. suiTar(Tharu) sweTar (English) 'sweater'

Derivation: Since morphology of this language is productive in nature, wordg can be formed by the process of derivation. For example - Adverb are formed from adjectives by affixing the suffix-se, e.g., Banihiyaa- 'good' >banihiyaa-se 'well, Jaldi- 'quick' >jaldi-se 'quickly'.

From verbs nouns are derived,e.g., Likh- to write >likhaai 'writing', Khel- to play >khel-aai 'playing', Haasto laugh >haas-aai 'laughing', Suffix -aai is used to derive a noun from a verb. Similarly, adjectives are formed from nouns by affixing the suffix - iyaa, e.g., Pahaar 'mountain' >pahariyaa 'belonging to the mountain', Citwan 'chitwan' > citwaniyaa 'belonging to chitwan'

Compounding: Compounding is another process of word formation in which two or more words combine, e.g., UparTar 'up and down', aTa-oTa 'here and there'

Reduplication: Reduplication process is also a major feature of Tharu language. So, it is one of the most important procedures of forming words. It is illustrated in the following examples:

(6) u ghare - ghare ge-lai, She /he house- RED go -PT 3 'He went to house.'

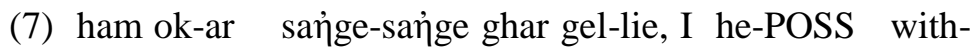
RED house go-PL1, 'I went to house withhim.' Reduplication is generally used to put emphasis.

Syntax: Left branching is the common feature of the South Asian languages (Masica, 1976). This feature is illustrated as follow: Gaai 'cow', ujar gaai 'white cow', ekTaa ujar gaai 'a white cow'. Generally, $2^{\text {nd }}$ Aryan languages are SOV or OV 
languages (masica, 1991). The basic order of major constituents of a sentence in Tharu, is SOV, e.g., raam bhaat khelkai 'Ram ate rice.'

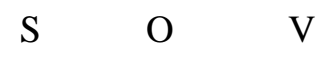

It is postpositional languages and grammatical functions are marked by postpositions (instrumental $-s e$, dative- $k e$, locative -me, and genitive - $k e$, there is considerable freedom of movements for NPs in a clause, it can be exploited for discourse functions such as topic, theme, or focus, for example the above sentence (9) can, sometimes, be uttered as bhaat khelkai raam, bhaat raam khelkai, khelkai raam bhaat, khelkai bhaat raam, raam khelkai bhaat.

\section{Structure of types of simple sentence}

The structure of a noun phrase (NP) can be presented in the following way : $\mathrm{NP}=$ demonstrative $)+($ possessive $)+$ (Adjective) + head noun.

A noun phrase in this language may consist of a head which is either a noun or a pronoun, e.g., $i$ kit ap 'this book' [demonstrative + head], ham-ar kitaap 'our book' [possessive + head], nik kitaap 'good book' [adjective + head], $i$ ham-ar kitaap 'this our book' [demonstrative + possessive + head], $i$ ham-ar nik kitaap 'this our good book' [demonstrative + possessive + adjective + head]

The simple sentences of this language can be divided into three types: declarative, interrogatives and imperative.

Declarative sentence: Declarative sentences refer to the verbs forms or sentence/clause typically used in expression of statements. The basic order of the major constituents remain same i.e. SOV. The following sentence illustrate the fact.

(9) ham bidyaarthi ci-e,I student be -NPT 1, 'I am student.' 
Interrogative sentence: In Tharu language, there are two types of interrogative questions yes/no questions and question woed question.

Yes/ NO Questions: The basic word order remains same. Declarative sentences are uttered with falling intonation whereas the yes/no questions are uttered with rising intonation (question intonation.

Sometimes yes/n(10) raam bhaat khel-kai ?, Ram rice eat PT 3, ' Did ram eat rice.' o questions are derived by adding a particle $k i$ at the beginning of the sentences, e.g., $k i$ raam bhaat khel-kai? PRT Ram rice eat-PT3?, 'Did ram eat rice?

Question word Questions: Like yes/no type questions, these sentences can be answered neither bi 'yes' nor by 'no'. So, these types of questions are open type questions, i.e. the question that require some answers rather than mere yes or no. The different questions word in Tharu language are - kathi 'what', ke 'who', koan 'which'. Kathek 'how much'. Kaithiyaa 'when', kakar 'whom' and kata/kate 'where'. These questions word are placed in the place of what answer is expected in the sentences.

(12) sita kate ge-lai? Sita where go-PT 3 'Where did sita go?

Imperative sentence: As the imperative sentence expresses direct commands, instructions or requests, it is solely restricted to the second person subject. The word order remains same but if the subject is pronoun, it is omitted and, obviously, it is second person i.e. 'you'.

(13) ghaas kaaT, Grass cut-IMP, 'Cut the grass.'The root of the verb is used to express imperative mood. But the affixes $\mathrm{u}$ and $-\mathrm{a}$ are used to mark honorificity. They are illustrated in the following examples :

(14) ghaas kat-a, grass cut- H. IMP, 'cut the grass.' 
(15) (apane) ciThi likh-u, (you. H) letter write- IMP . H 'Write a letter.'

Types of compound sentence: Different sentences combine into a single sentence in different ways and compound sentences are formed. They can be divided into coordinate and subordinate types.

Coordinate compound sentence: Coordinating conjunctions join units of equal status/ sentences. There are different kinds of coordinating conjunctions. This language clearly shows the use of additive and alternative conjunctions.

Additive: $a a$ is an additive type of coordinating conjunction in Tharu language.

(16) a. raam sut-lai, Ram sleep -PT 3, 'Ram slept.'

b. hari sut-lai, Hari sleep -PT 3, 'Hari slept.'

c. raam aa hari sut-lai, Ram and hari sleep-PT 3

'Ram and hari slept.'

In the above illustration, sentence (16a) and (16b) are combine to form compound sentence (16c) with the additive conjunctive particle $a a$.

Alternative: In this language, there are two kinds of alternative coordinating constructions. They are yaa 'or' kita 'either......or'

(17) a. u-sab/sun raajbiraaj-me thahar-lai, S/he-PL Rajbiraj-LOC stay-PT 3, They stayed in rajbiraj.

b. $u$-sab/sun pokharaa-me thahar lai, she/he -PL pokaraLOC stay -PT 3, 'They stayed in pokhara.'

c. $u$-sab /sun raajbiraaj-me yaa pokharaa-me thahar-lai, s/he-PL Rajbiraj-LOC CON pokhara -LOC stay p3, 'They stayed in Rajbiraj or Pokhara.'

In the above illustration, sentences (17a) and (17b) are combined to form (17c) with the help of alternative conjunctive particle yaa. 
Subordinate compound sentence: Tharu language has different subordinating conjunctions. They are regulative, causal, purposive, conditional, concessive and relative clause.

Resultive: teidwaare 'therefore' is a resultative conjunction. It links two different sentences. It follows the statement which proves the result of something. In the following examples, sentence (18a) and (18b) combine to form (18c) ith teidwaare.

(18) u canasgar ch-ai s/he intelligent be -PT 3

'He/she was intelligent.' $u$ banihiyaa ank paab-lkai, s/he good mark get-PT 3 He/She got good marks. u canasgar ch-ai taidwaare $u$ banihiyaa ank paab-lka s/he intelligent be-PT 3 CON s/he good mark get-PT 'He/She was intelligent, therefor, she/he got good marks.'

Causal: In Tharu language, the causal conjunction is kathile ta. It expresses or indicates a cause due to which something did or did not happen.

(19) u paDh-aile iskul nai e-lai s/he read-INF school NEG come-PT 3 He did not come to school to read. u bimaar chai s/he ill be- PT 3 He was ill. u paDh-aile iskul nai e-lai kathile ta $\mathrm{u}$ bimaar ch-ai s/heread-INF school NEG-comePT3 CON s/he ill be-PT 3 'He did not come to school to read because he was ill.' Sentences (19a) and (19b) are combining with the subordinating conjunction $k_{\partial}$ thile $t_{2}$ to form (19c).

Purposive: In Tharu language, the purposive conjunction is lel 'for'. It is placed after the infinitive form of the verb as in the examples. However, the infinitives form itself also functions as purposive as in the example.

(20) u paisa kamaa -ike lel parha - lkai, s/he money earn INF for read -PT3, 'He read in order to earn money.' 
Conditional: Yadi and agar are the conditional subordination conjunctions. Both of them refer to it. They are illustrated in the examples. (21) yadi ham mamaa-ke ghar nai-ge-lie ta $y$ I kaam if I uncle-GEN house NEG-go-PT 3 then this work nai-puraa kair sa-ci-e NEG-complete do finish-NPT 3

'If I did not go to my uncles house, I would not be able to complete this work.'The above sentence has to clauses, ham mamaa-ke ghar nai-ge-lie 'I did not go to uncle's house' and I kaam nai-puraa kair sak-ci-e 'This work would not be complete' with yedi.....ta where the the first claise is subordinate and the second one is superordinate.

Concesseve: Tabone, ke and bhelpar are concessive conjunctions which mean although/ in siite of, e.g. (22) raam dos bhyaa ke hamarse jhagaraa kar-lkai Ram friend be CON me qurrel do-PT 3 'Ram quarreled with me even though he was my friend.' The above sentences (22) has two clauses, ram dos bhaya 'Ram was friend' and ram hamarse jhagaraa karlkai 'Ram fought me', with the help of concessive conjunctions $k e$.

Relative clause: In Tharu language, the relative clause is formed by using the relative pronouns. The sentence $(23 \mathrm{c})$ is formed by combining sentences (23a) and (23b) with the relative pronoun je.(23) a. ham ciThi likh-lie I letter writePT 1, 'I wrote letter.' u ciThi nai-pug-la that letter NEGreach-PT3 'That letter does not reach.' ham je ciThi likh-lie $u$ ciThi na-pug-lai I REL letter write -PY 1 that letter NEG reach-PT 'The letter which I wrote did not reach.'

\section{Abbreviations}

1 : first person IMP : imperative

$2 \quad$ : second person IMPERF : imperfective

3 : third person INF : infinitive 


$\begin{array}{llcl}\text { C } & \text { : constant } & \text { LOC } & \text { : locative } \\ \text { CON } & \text { : conjunction } & \text { NEG } & \text { : negative } \\ \text { H } & \text { : honorific } & \text { NPT } & \text { : non past tense } \\ \text { O } & \text { : object } & \text { RED } & \text { : reduplicative } \\ \text { POSS } & : \text { possessive } & \text { REL } & \text { : relative pronoun } \\ \text { PROB } & : \text { probabilitive } & \text { S } & \text { : subject } \\ \text { PRT } & : \text { particle } & \text { V } & \text { : verb } \\ \text { PT } & : \text { past tense } & & \end{array}$

\section{References}

Bhandari, B. Chaudhary and etal(ed.) Languages of the world: modern Indo-Aryan languages, Moscow.

Boem, E.D. 1997. A phonological reconstruction of protoTharu, M. A. thesis, Universal of Texas at Arlington

Chaudhary MK. 2005. A sketch grammar of Saptariya Tharu, M.A. thesis, T.U

Chaudhary, AK. 2060 BS. Tharu language: a sociolinguistic survey, MA. thesis, T.U.

Chaudhary MK (2008). Causativization in Tharu, Central Department of Linguistics Tribhuvan University, Kirtipur

Chaudhary M.K (2010). Mood in Tharu, Department of Linguistics Bharthiar University, Coimbotore India

Bandhu, C. (2052). Nepali bhaasharuko Utpati (Origin of Nepali language), Kathmandu: sajha prakashan.

Chaudhary M.K. (2011). Co-ordination in Tharu, Central Institute of Indian Languages Mysore

Kroegar, Paul R. (2005). Analyzing grammar: an introduction, Cambridge: Cambridge University press.

Kumar, A. 2003. Tharu aur rastrabhaashaa Hindi: ek sanslesanatmak bislesam, (Tharu and national language Hindi: an analysis)

Masica, CP. (1976). Defining a linguistic area: South Asia, Chicago; University press of Chicago 
... .. (1991). The Indo Aryan languages, Cambridge: Cambridge University Press.

Pokharel, B.K (2050). Raastra Bhaashaa (National language). Kathmandu: Ratna pustak bhandar Yadava, Y.P (2003). 'Language' Population monograph of Nepal, Vol.1.kathamandu: CBS/HMG, Nepal. 